\title{
Gedanken zur Müdigkeitsgesellschaft
}

Enrico Danieli

\section{«Gefahr besteht, dass das heutige Leben in einer}

tödlichen Hyperaktivität endet, wenn ihm jegliche Ruhe verboten wird.»

Korrespondenz: Dr. med. Enrico Danieli Via ai Colli 22

CH-6648 Minusio Tel. 0917434789

e.b.danieli@bluewin.ch
Ob das neue Jahrhundert auch zu neuen Krankheiten, sogenannten Leitkrankheiten, führt? So scheint es, dass die Zeit der immunologischen Erkrankungen vorüber ist, dafür neuronale Pathologien (Depression, ADHS, Burn-out usw.) Grundlagen für neue Leiden darstellen.

Das Fremde, so noch bis vor wenigen Jahren, ist heute nicht mehr fremd, sondern das Gleiche. Das immunologisch Andere (z. B. Viren) war früher die Negativität. Das Verschwinden der Andersheit (im Rahmen der Globalisierung wird alles gleich) bedeutet, dass wir in einer Zeit leben, die arm ist an Negativität, die neuronalen Erkrankungen unseres Jahrhunderts folgen daher der Dialektik der Positivität: Pathologische Zustände beruhen auf einem Übermass an Positivität oder Möglichkeiten. Gewalt geht demgemäss vom Gleichen aus. Das Gleiche führt aber nicht zu Antikörpern. Wir leiden an einem Zuviel an Gleichem, an einem Übermass an Positivem. Die neuronale Gewalt ist ganz ohne Negativität, sie ist systemisch, dem System immanent. Neuronale Erkrankungen sind ein Übermass an Positivität: eine Überhitzung bei zu viel des Gleichen.

Die heutige Gesellschaft ist nicht mehr wie vor wenigen Jahren eine Disziplinargesellschaft (alles unterliegt Befehlen, dem Sollen und dem Nicht-Dürfen), sondern eine einzige Leistungsgesellschaft: Wir sind Unternehmer unserer selbst. Das entgrenzte Können ist unser Verb (yes wie can: der Slogan des Positivitätscharakters der Leistungsgesellschaft); der Arbeitsexzess führt zur Selbstausbeutung. So wird Ausbeutung

auch ohne Herrschaft möglich. Die Positivität des Könnens ist stärker als die Negativität des Sollens. Der Depressive ist erschöpft von der übermässigen Anstrengung, er selbst werden zu müssen.

Die systemische Gewalt der Leistungsgesellschaft ruft psychische Infarkte hervor. Nicht das Selbst ist erschöpft, sondern die Seele. Der depressive Mensch beutet sich selbst aus, er ist Täter und Opfer in einem. Die Depression bricht dann aus, wenn der Mensch nicht mehr können kann. Das Übermass an Positivität äussert sich auch als Flut von Reizen (Informationen usw.). Nur Formen oder Zustände der Dauer entziehen sich der Hyperaktivität: Gefahr besteht, dass das heu-

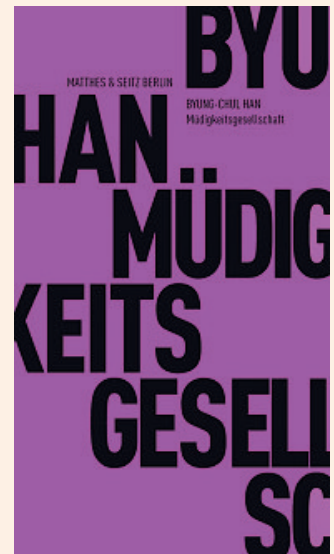

Byung-Chul Han Müdigkeitsgesellschaft

Berlin: Matthes \& Seitz Verlag; 2010. 72 Seiten. 15.90 CHF. SBN 978-3-88221-616-5

tige Leben in einer tödlichen Hyperaktivität endet, wenn ihm jegliche Ruhe verboten wird. Nervosität und krankmachende Unruhe überwiegen, wenn nichts Dauer und Ruhe verspricht. Ein Erschöpfungssymptom ist, wenn Reizen kein Widerstand mehr geboten werden kann. Helfen kann nur eine vita contemplativa: ein Neinsagen ist aktiver als jede Hyperaktivität. Zu lernen wäre, nicht jedem Reiz zu folgen: zu zögern, innezuhalten, dem Jetzt ein Nein entgegenzusetzen. Nein sagen ist souveränes Tun und aktiver als jede Hyperaktivität. Es ist eine Illusion zu glauben, umso freier zu sein, je aktiver man ist («aktiv bis ins hohe Alter...»).

Im Zuge der Positivisierung der Welt verwandeln sich Gesellschaft und Mensch in eine autistische Leistungsmaschine. Die positive Potenz ist die Potenz, etwas zu tun, die negative ist die, nicht zu tun. Die Last des spätmodernen Imperativs macht krank, sie führt zu einer Überstrapazierung des Ichs, zu einer depressiven Ich-Müdigkeit. Die Leistungsgesellschaft entwickelt sich neuerdings $\mathrm{zu}$ einer Dopinggesellschaft (Neuroenhancement): Doping heisst Leistung ohne Leistung. Als Kehrseite davon erzeugt die Aktivgesellschaft exzessive Müdigkeit, Überforderung und Erschöpfung. Das Viel-zu-Viel an Leistung, das Übermass an Positivität führt demgemässs zum Infarkt der Seele (der Gesellschaft). Die Erschöpfungsmüdigkeit ist eine Müdigkeit der positiven Potenz, sie macht unfähig, etwas zu tun. Die Müdigkeit aber, die inspiriert, ist eine Müdigkeit der negativen Potenz, nämlich des Nicht-zu: ein Zustand, der befreit von jedem Um-zu. Die negative Potenz ist eine Zwischenzeit, heilig ist nicht der Tag, um zu (tun), sondern um nicht zu (tun). So wird die kommende Gesellschaft, bei weiter ungezügelter Leistungsbereitschaft, nichts anderes sein als eine Müdigkeitsgesellschaft. 